\title{
KHẢO SÁT LỖI BIÊN DỊCH CỦA SINH VIÊN \\ NĂM THỨ BA TRƯỜNG ĐẠI HỌC NGOẠI NGŨ๋ \\ - ĐẠI HỌC QUỐC GIA HÀ NỘI
}

\author{
Đỗ Thúy Hằng* \\ Khoa Ngôn ngũ và Văn hóa Hàn Quốc, Trưòng Đại học Ngoại ngũu, ĐHQGHN, \\ Phạm Văn Đồng, Cầu Giấy, Hà Nội, Việt Nam \\ Nhận bài ngày 25 tháng 12 năm 2017 \\ Chỉnh sửa ngày 22 tháng 01 năm 2018; Chấp nhận đăng ngày 24 tháng 01 năm 2018
}

Tóm tắt: Bài viết trình bày nghiên cứu khảo sát các lỗi biên dịch trong các bản dịch của sinh viên năm thứ ba tại Trường Đại học Ngoại ngữ - Đại học Quốc gia Hà Nội (ĐHQGHN). Trên cơ sở khung phân tích lỗi biên dịch về nội dung và hình thức, nhóm tác giả phân tích các bản dịch của 406 bài tập biên dịch từ tuần 1 đến tuần 7 và các bài kiểm tra giữa học kỳ $\mathrm{I}$ của 58 sinh viên năm học 2017-2018, qua đó chỉ ra nguyên nhân các lỗi biên dịch về nội dung như lỗi ngữ pháp, lựa chọn từ, văn phong, ngữ dụng và các lỗi về hình thức liên quan đến vấn đề kỹ thuật. Từ kết quả phân tích, nhóm tác giả đưa ra những đề xuất nhằm nâng cao chất lượng dạy - học trong các giờ học biên dịch tiếp theo.

Tì khóa: lỗi, biên dịch, tiếng Hàn

\section{Dẫn nhập}

Trong khung chương trình đào tạo đại học chính quy theo hệ chuẩn của Trường Đại học Ngoại ngữ - ĐHQGHN, hiện nay có hai ngành đào tạo là ngành sư phạm và ngành ngôn ngữ. Trong đó, định hướng biên - phiên dịch là định hướng quan trọng đối với tất cả các ngôn ngữ được giảng dạy tại Nhà trường ${ }^{(1)}$.

Các học phần chuyên ngành được giảng dạy cho sinh viên chủ yếu vào năm thứ ba và năm thứ tư. Học phần "Biên dịch" tại Khoa Ngôn ngữ và Văn hóa Hàn Quốc là học phần được đưa vào chương trình học kỳ I của năm thứ ba. Đây là học kỳ đầu tiên sinh viên được tiếp xúc với các học phần liên quan đến biên - phiên dịch gồm: "Lý thuyết dịch", "Phiên dịch" và "Biên dịch".

Trong nghiên cứu này, chúng tôi đưa ra kết quả khảo sát bài tập biên dịch của 58 sinh viên năm thứ ba (QH.2015) của Khoa Ngôn ngữ và Văn hóa Hàn Quốc, Trường Đại học Ngoại ngữ - ĐHQGHN, học kỳ I năm học 2017-2018 đối

\footnotetext{
*ĐT.: 84-1677992473

Email: hang2009nt@gmail.com

http://daotao.ulis.vnu.edu.vn/cac-chuong-trinh-daotao-dai-hoc-chinh-quy/
}

với học phần "Biên dịch" từ tuần thứ 1 đến tuần thứ 7 . Trên cơ sở phân tích định lượng và định tính, chúng tôi chỉ ra những lỗi biên dịch thường gặp của sinh viên, phân tích nguyên nhân và đưa ra một số đề xuất sư phạm nhằm mục đích nâng cao chất lượng dạy - học học phần này.

Giáo trình được sử dụng trong học phần này là giáo trình "Biên dịch" đã nghiệm thu cấp trường năm 2015 của tác giả Nguyễn Thùy Dương. Đây là cuốn giáo trình cung cấp cho sinh viên các chủ đề dịch phong phú trên nhiều loại hình văn bản như dịch thư tín, công văn, hợp đồng, thông báo, quảng cáo, các nội dung về văn hóa, kinh tế, xã hội, hợp đồng lao động, quy định thành lập công ty, bài phát biểu, v.v... Các bài học được thiết kế luân phiên đối với việc dịch ngược và dịch xuôi.

Trước đây, trong các giờ học biên dịch, sinh viên thường viết tay bài tập của mình. Tuy nhiên, căn cứ theo yêu cầu thực tế đối với một biên dịch viên, trong học kỳ này người học được yêu cầu thực hiện việc biên dịch trên máy tính ${ }^{(2)}$ nhằm rèn luyện các kỹ năng

\footnotetext{
${ }^{2}$ Máy tính xách tay do người học tự trang bị sau khi khảo sát cho kết quả: 54/58 sinh viên có máy tính xách tay, 4/58 sinh viên có thể mượn máy tính xách tay để sử dụng.
} 
văn bản thành thạo; đồng thời cũng tạo cơ hội cho giảng viên phát hiện và hướng dẫn sinh viên chỉnh sửa bài biên dịch của mình về cả mặt hình thức chứ không chỉ dừng lại ở việc hướng dẫn chỉnh sửa nội dung như trước.

\section{Các tiêu chí đánh giá bản dịch}

Massoud (1988: 19-24) đặt ra các tiêu chí cho một bản dịch tốt như sau: "là một bản dịch dễ hiểu; là một bản dịch gãy gon và luu loát; là một bản dịch sử dụng các cưm tù phổ biến hoặc thành ngữ; truyền đạt, đến múc độ nào đó, sư tinh tế của văn bản gốc; có khả năng phân biệt ngôn tù ẩn du và ngôn ngũ văn chương; là một bản dịch có thể dưng lại bối cảnh văn hóallịch sủ của văn bản gốc; dịch rõ ràng nhũng chĩ viết tắt, và các tì̀, cưm tì̀ phiếm chỉ, bài hát, và lời ru; là bản dịch truyền tải càng nhiều càng tốt ý nghĩa của văn bản gốc".

El Shafey (1985: 83) lại đưa ra các tiêu chí khác đối với người dịch và một bản dịch tốt, đó là: "kiến thức về ngũ pháp của ngôn ngũu" nguồn cộng với kiến thức về tù vựng, cũng nhu sư hiểu biết tốt về văn bản cần dịch; khả năng của nguời dịch trong việc chuyển thể văn bản cần dịch (văn bản ngôn ngũu nguồn) sang ngôn ngĩu đích; bản dịch cần nắm bắt đurợc phong cách hoạc văn phong của văn bản gốc, bản dịch cần truyền tải được thông điệp của văn bản cần dịch".

El Zeini (1994: xvii) đề xuất một mô hình thực tế để đánh giá chất lượng trong dịch thuật, bà đặt các tiêu chí về nội dung cũng như các tiêu chí về phong cách trong dịch thuật ở vị trí quan trọng ngang nhau. Mô hình này bao gồm một tập hợp các tiêu chuẩn chính: tiêu chuẩn liên quan đến nội dung và tiêu chuẩn liên quan đến hình thức. Bà hy vọng "dịch giả có thể giảm thiểu được các lỗi hoạc thiệt hại mà các lồi dịch này mang lại, cũng nhu loại bỏ được các vấn đề về việc nội dung bản dịch không trong sáng".

Như vậy, trong khi Massoud (1988) và El Shafey (1985) quan tâm đến chất lượng bản dịch trên khía cạnh nội dung, kiến thức về từ vựng, ngữ pháp hoặc kiến thức nền thì El Zeini (1994) chú ý đến cả hai tiêu chí nội dung và hình thức.

Trong một nghiên cứu khảo sát lỗi dịch thuật trong các biển báo, Nguyễn Thị Minh Tâm và các cộng sự (2017: 90-104) đưa ra 4 tiêu chí đánh giá bản dịch dựa trên mô hình phân tích bản dịch của Munoz (2012) và Keshavarz (1993) bao gồm các vấn đề sau: vấn đề về chính tả, ngữ pháp; vấn đề về lựa chọn từ vựng (từ và cấu trúc); vấn đề về nội dung dịch; ngữ dụng và phong cách ngôn ngữ. Nhu vậy ngoài vấn đề về chính tả, Nguyễn Thị Minh Tâm và các cộng sự có thiên hướng phân tích bản dịch về mặt nội dung hơn là hình thức.

Trong nghiên cứu này, nhóm tác giả kết hợp khung phân tích lỗi biên dịch của El Zeini (1994) và khung phân tích lỗi biên dịch của Nguyễn Thị Minh Tâm và các cộng sự (2017) theo hai tiêu chí về nội dung và hình thức để xây dựng khung phân tích lỗi biên dịch nhu mô hình ở Bảng 1 dưới đây:

Bảng 1 . Khung phân tích lỗi biên dịch của sinh viên năm thứ ba học kỳ I

\begin{tabular}{|c|c|c|c|c|c|c|c|c|c|}
\hline & & & \multicolumn{5}{|c|}{ Bản dịch của sinh viên } & & \\
\hline \multicolumn{5}{|c|}{ Lỗi về nội dung } & \multicolumn{5}{|c|}{ Lỗi về hình thức } \\
\hline$\downarrow$ & $\downarrow$ & $\downarrow$ & $\downarrow$ & $\downarrow$ & $\downarrow$ & $\downarrow$ & $\downarrow$ & $\downarrow$ & $\downarrow$ \\
\hline $\begin{array}{l}\text { Lỗi } \\
\text { ngữ } \\
\text { pháp }\end{array}$ & $\begin{array}{c}\text { Lỗi } \\
\text { chọn } \\
\text { lọc từ }\end{array}$ & $\begin{array}{l}\text { Lồi văn } \\
\text { phong } \\
\text { nói/ viết }\end{array}$ & $\begin{array}{l}\text { Lỗi } \\
\text { ngữ } \\
\text { dụng }\end{array}$ & $\begin{array}{l}\text { Lỗi dịch } \\
\text { thừa/ } \\
\text { thiếu/ sai } \\
\text { nội dung }\end{array}$ & $\begin{array}{l}\text { Không } \\
\text { căn } \\
\text { chỉnh } \\
\text { lề }\end{array}$ & $\begin{array}{l}\text { Không } \\
\text { căn } \\
\text { chỉnh } \\
\text { giãn } \\
\text { dòng }\end{array}$ & $\begin{array}{l}\text { Không } \\
\text { căn } \\
\text { chỉnh } \\
\text { phông } \\
\text { chữ }\end{array}$ & $\begin{array}{l}\text { Không sử } \\
\text { dụng đúng } \\
\text { định dạng } \\
\text { của văn } \\
\text { bản gốc }\end{array}$ & $\begin{array}{c}\text { Sai } \\
\text { chính } \\
\text { tả }\end{array}$ \\
\hline
\end{tabular}




\section{Thu thập dữ liệu và phân tích những lỗi biên dịch thường gặp của sinh viên}

\subsection{Thu thập dĩu liệu}

Dữ liệu thu thập cho nghiên cứu này là 406 bài biên dịch từ tuần 1 đến tuần 7 , học kỳ I năm học 2017-2018, của 58 sinh viên năm thứ ba (QH.2015), Khoa Ngôn ngữ và Văn hóa Hàn Quốc, Trường Đại học Ngoại ngữ - ĐHQGHN với 7 chủ đề dịch: Mẫu thư tín, công văn, hợp đồng; Thông báo, quảng cáo; Văn hóa Hàn Quốc; Các cơ quan hành chính và thủ tục hành chính của Hàn Quốc; Các vấn đề kinh tế - xã hội; Hợp đồng lao động; Những quy định chung về thành lập công ty liên doanh.

Ngoài ra, chúng tôi cũng thu thập dữ liệu là 58 bài kiểm tra giữa kỳ thực hiện vào tuần 8 để so sánh với kết quả phân tích bài biên dịch của sinh viên trong 7 tuần trước đó.

Các bản dịch của sinh viên chúng tôi đưa ra làm minh họa dưới đây có thể tồn tại nhiều lỗi trong cùng một bản dịch. Tuy nhiên, để tránh tản mạn, chúng tôi sẽ chỉ tập trung vào dạng lỗi đang được phân tích.

\subsection{Lỗi biên dịch về nội dung}

\section{* Lối ngũ pháp}

\section{+ Sư dụng sai tiểu tù}

• Văn bản nguồn (1): "Hiện tại đơn vị tiền tệ đang được sử dụng tại Hàn Quốc là đồng “Won". Đơn vị tiền này có nghĩa là tròn, dùng để chỉ hình dáng tròn của đồng tiền xu."

Bản dịch của sinh viên (1-1): "현재 한국의 사용하는 통화 단위는 “원”이다. 이 통화 단위는 원형를 의미한다. 즉 주화를 보면 원형에 대해 생각한다."

Bản dịch của sinh viên (1-2): "현재 한국에서 사용되고 있는 화폐의 단위는 “원"이다. 동그랗다는 원의 의미이고 동그란 동전의 모양에 가리킨다."

Trong bản dịch (1-1), sinh viên đã dùng tiểu từ "의" chỉ sở hữu cho từ "tại", trong khi tiểu từ phù hợp là “에서” để thể hiện "tại đâu diễn ra hành động gì" và tiểu từ tân ngữ đứng sau “원형” là danh từ có phụ âm cuối (patchim) lẽ ra phải là "을" thì người dịch đã dùng nhầm thành tiểu từ "를" dành cho tân ngữ không có phụ âm cuối. Trong bản dịch (1-2), sinh viên đã dùng tiểu từ "에" thay vì sử dụng tiểu từ " 을/를" để thể hiện vai trò tân ngữ của "모양".

Gợi ý cách dịch (1'): “현재 한국에서 사용하고 있는 돈의 단위는 “원”이다. 이 단위는 “동글다"란 뜻을 지니고 있는데, 이는 주화가 둥근 데서 따온 말이다."

• Văn bản nguồn (2): "Tùy theo chất liệu làm ra tiền, người ta sẽ gọi là tiền xu hay tiền giấy."

Bản dịch của sinh viên (2-1): "돈은 만든 재료로 주화나 지폐이라고 된다.”

Trong bản dịch này, sinh viên đã lựa chọn tiểu từ “로” để diễn đạt nghĩa "tùy theo", trong khi tiểu từ này thường được dùng với nghĩa là "bằng (phương tiện, chất liệu gì)" hoặc để chỉ phương hướng, chỉ sự biến đổi.

Gợi ý cách dịch (2'): “돈을 만든 재료에 따라 주화와 지폐로 나뉜다."

Các minh họa trên cho thấy tuy sinh viên tham gia học phần "Biên dịch" đã trải qua 4 học kỳ tập trung vào việc học thực hành tiếng nhưng lỗi lựa chọn tiểu từ chưa phù hợp vẫn là một trong những lỗi phổ biến, chiếm tỉ lệ trung bình $66,7 \%$ trong tổng số bài dịch của sinh viên. Điều này có thể xuất phát từ việc sinh viên chưa nắm vững ý nghĩa và cách sử dụng các tiểu từ trong tiếng Hàn. Họ cần có thêm nhiều cơ hội để luyện tập và sử dụng chính xác các tiểu từ rất đa dạng trong ngôn ngữ này.

\section{+ Lối chia động tù}

- Văn bản nguồn (3): "Đến những năm 2000, đầu tư nước ngoài bắt đầu phục hồi và tăng mạnh.”

Bản dịch của sinh viên (3-1): “2000 년대부터 외국투자는 다시 회복하며 크게 올라하였다."

Trong bản dịch trên, thay vì chia động từ “ 오르다" (tăng) là "올랐다" thì người học đã 
tư duy đây là động từ kết thúc bằng "하다" nên đã chia thành "올라하였다". Ngoài minh họa trên, còn có trường hợp sinh viên chia động từ "고치다" là “고치하였고..." hay “고치하되고...”. Điều này phản ánh trong quá trình tư duy về chia động từ trong tiếng Hàn, người học có sự nhầm lẫn giữa động từ thuần Hàn, động từ có gốc chữ Hán kết thúc bằng 하다 và động từ chủ động với động từ bị động.

Gợi ý cách dịch (3'): “2000년대에 들어 외국인 직접 투자는 회복되어 다시 증가하고 있다."

\section{+ Lối về trật tụ câu, cum tù}

- Văn bản nguồn (4): “지원 기간: 2011. 7. 11(월) 7. 22(금)"

Bản dịch của sinh viên (4-1): "Thời gian đăng ký: 2011/7/11 (thứ 2) đến 7/22 (thứ 6)”

Trong bản dịch trên, sinh viên đã không chú ý trong tiếng Hàn khi nói về thời gian sẽ sắp xếp theo trình tự từ lớn đến nhỏ (năm/ tháng/ngày) trong khi tiếng Việt sắp xếp theo trình tự từ nhỏ đến lớn (ngày/tháng/năm). Ngoài ra, vì tiếng Hàn sắp xếp trình tự thời gian từ lớn đến nhỏ nên có thể viết năm đứng đầu để dùng chung cho hai trường thông tin về thời điểm là "2011.7.11 7.22" nhưng khi dịch sang tiếng Việt, bản dịch nên viết năm ở vế sau thành (4') "Thời gian đăng ký: 11/7 (Thứ Hai) 22/7/2011 (Thứ Sáu)" sẽ hợp lý hơn cho người theo dõi.

Trong một trường hợp khác, văn bản nguồn (5) là: "Có 77 quốc gia có công ty đầu tư vào Việt Nam, trong đó có Hàn Quốc." thì bản dịch của sinh viên (5-1) là: “국가 77 개에서 오고 베트남에서 투자하고 있는 회사들 중에 한국도 있다."

Ở bản dịch này, thay vì sắp xếp trình tự "77개 국가" thì sinh viên đã để trình tự là “국가 77 개". Qua minh họa này cho thấy, 4 học kỳ tập trung vào việc học thực hành tiếng có thể vẫn chưa là khoảng thời gian đủ để sinh viên nhận thức, ghi nhớ và sử dụng chính xác trật tự câu, trình tự sắp xếp các cụm danh từ, động từ trong tiếng Hàn.
Gợi ý cách dịch (5'): “투자기업의 국적은 한국 등 약 70 개 국가에 달한다."

\section{+ Lối cấu trúc}

Các văn bản tiếng Hàn thường có sự xuất hiện nhiều của các cụm danh từ trong khi các văn bản tiếng Việt thường có xu hướng dùng các cụm động từ. Trong khi dịch văn bản, người học mắc lỗi khi giữ nguyên cấu trúc trong văn bản gốc, khiến người đọc cảm thấy khó hiểu.

- Văn bản nguồn (6): “Giá chung cư tăng vọt do việc phát triển đô thị mới"

Bản dịch của sinh viên (6-1): “새도시 개발로 인해 아파트 임대를 늘어난다"

Văn bản nguồn ở đây là nhan đề một bài báo đã được dịch giữ nguyên phong cách tiếng Việt và kết thúc câu bằng động từ. Trong khi đó, các nhan đề bài báo trong tiếng Hàn thường được đặt dưới dạng cụm danh từ, vì thế bản dịch sẽ tạo cảm giác lạ lẫm với người theo dõi bản dịch.

Gợi ý cách dịch (6’): “신도시 개발로 아파트 값 급등"

- Văn bản nguồn (7): "Sinh ngày..... tháng.....năm. tại: ,

Bản dịch của sinh viên (7-1): "생일: 년.....월..... 일 에서"

Văn bản nguồn trên trích trong hợp đồng lao động, tuy ngắn gọn nhưng khoảng $56,8 \%$ sinh viên đã không lựa chọn cách chuyển dịch sang cựm danh từ trong tiếng Hàn. Việc kết thúc câu bằng tiểu từ "에서" không kèm theo động từ để thể hiện "ở đâu diễn ra hành động gì thật sự sẽ làm cho người bản ngữ không hiểu ý đồ của văn bản dịch là gì.

Gợi ý cách dịch (7'): “생년월일: 출생지:

\section{* Lồi lưa chọn tì}

- Văn bản nguồn (8): “홍보관은 2008 년 1 월 3 일자 하 꿱 반 과장님 서한문에 첨부된 도면을 기준으로 스포츠 경마장 부속 가건물에 홍강 관련 전시 모형도, 동영상 등을 설치하고 (...)" (Trích luợc)

Bản dịch của sinh viên (8-1): "Với tiêu chuẩn là bản vẽ đính kèm thư ngỏ của trưởng phòng Hà Quốc Văn, vào ngày 3 tháng 1 năm 2008, phòng quảng bá sẽ thiết lập các bản vẽ mô hình trưng 
bày và video,... liên quan đến sông Hồng ở tòa nhà thuộc trường đua ngựa thể thao (...)”

Trong bản dịch này, các từ "서한문", “가건물”, “설치하다” lần lượt được dịch là "thư ngỏ", "tòa nhà", "thiết lập". “서한문" trong tiếng Hàn được giải thích là "Một hình thức thư trong đó sử dụng kính ngữ với đối phương và sử dụng các từ khiêm nhường để nói về mình."(3) Vì vậy, việc chuyển nghĩa “서한문" trong trường hợp này thành "thư ngỏ" dường như chưa hợp lý. Còn từ "가건물 (假建物)" nếu chỉ dịch là "tòa nhà" mà không có chữ "tạm" thì chưa thể hiện đầy đủ ý nghĩa của chữ 假 theo nghĩa “tạm thời” ở đây. Từ "설치하다" được dịch là "thiết lập" có lẽ do người dịch đang tư duy sang từ "설립하다" và cũng chưa có sự rà soát cẩn thận nội dung bản dịch sau khi hoàn thành.

Gợi ý cách dịch (8'): "Phòng trưng bày được lắp đặt mô hình trưng bày, hệ thống hình ảnh động về sông Hồng bên trong tòa nhà tạm thuộc trường đua ngựa thể thao theo tiêu chuẩn bản thiết kế được đính kèm trong bức thư mà trưởng phòng Hà Quốc Văn đã gửi ngày 3 tháng 1 năm 2008 (...)"

- Văn bản nguồn (9): "Việt Nam đã cho ra bộ luật đầu tư nước ngoài liên quan đến đầu tư trực tiếp của các doanh nghiệp nước ngoài vào tháng 12/1987 và sửa đổi thành bộ luật đầu tư mới vào tháng 11/1996."

Bản dịch của sinh viên (9-1): “베트남은 외국업제의 직접투자에 관련된 외국 투자법을 1987년 12월에 발행했으며 1996년 11월에 이 법을 고쳐서 새로운 투자법이 되었다."

Như vậy, từ "cho ra (bộ luật)" với ý nghĩa "xây dựng (bộ luật)" đã được sinh viên dịch bằng từ "발행하다". Từ này thường được hiểu là "phát hành" trong các trường hợp như phát hành tiền, ấn phẩm, hóa đơn, ... Đối với từ "sửa đổi”, bản dịch sử dụng từ “고치다". "고치다” xét về ngữ nghĩa "sửa / sửa chữa" không làm cho người đọc bản dịch hiểu sai nội dung cần truyền tải;

3 네이버 국어사전: http://krdic.naver.com tuy nhiên, “고치다” thường được sử dụng với ý nghĩa "sửa đồ bị hỏng", "sửa cái gì bị sai". Trong tiếng Hàn, sinh viên có thể dễ mắc lỗi khi lựa chọn và sử dụng các từ "고치다", "수정하다”, "수리하다”, "수선하다”, "개정하다”... trong các trường hợp sửa đồ vật bị hỏng / bị làm sai, sửa chữa văn bản, sửa chữa máy móc, sửa quần áo / giầy dép, sửa đổi luật... Có thể thấy, lỗi về chọn lọc từ trong quá trình biên dịch có thể xuất phát từ việc người dịch chưa có khả năng sử dụng ngôn ngữ một cách thành thục hoặc có thể có nguyên nhân từ việc phân tích văn bản gốc chưa sâu sắc, thấu đáo. Vì vậy, thiết nghĩ, trong quá trình dạy - học, giáo viên cần hướng dẫn cho sinh viên và sinh viên cũng cần tìm hiểu thêm về các trường từ vựng, các từ vựng liên quan và dễ bị nhầm lẫn trong giao tiếp cũng như trong công tác biên phiên dịch.

Gợi ý cách dịch (9’): “베트남의 외국인 직접투자에 관련한 외국 투자법이 1987년 12월에 제정되어 1996년 11월 '신투자법' 으로 개정되었다."

\section{* Lối văn phong nói / viết}

- Văn bản nguồn (10): "Chúng tôi, một bên là:............. Quốc tịch:............."

Bản dịch của sinh viên (10-1): “우리, 한쪽..................국적..........."

Bản dịch của sinh viên (10-2): “우리, 한편은................국적..........."

Văn bản gốc trên xuất hiện trong một bản hợp đồng lao động, nội dung rất ngắn gọn và nhìn qua thì dường như không có gì khó khăn trong quá trình biên dịch. Tuy nhiên, trong cả hai bản dịch minh họa đều xuất hiện lỗi văn phong ở từ "một bên". Khi nhắc đến từ “埾” thường sẽ được hiểu là "bên / phía / đằng" liên quan đến chỉ vị trí như bên trái, bên phải, đằng này, đằng kia... và từ "편" ngoài chỉ "bên / phía" còn có ý nghĩa là "phe (ai)". Vì vậy, hai từ này không phải là từ phù hợp để sử dụng cho văn phong văn bản cần có sự trang trọng, lịch sự.

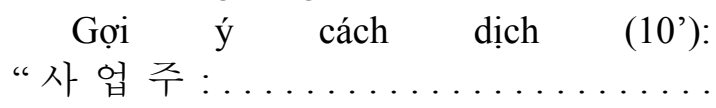
국적:. 
- Văn bản nguồn (11): “편지나 소포를 보낼 때는 우체국을 이용합니다. 우체국에서는 국내우편, 국제우편을 취급하며, 은행과 같은 금융업무도 본다."

Bản dịch của sinh viên (11-1): "Bưu điện thì tiếp nhận và vận chuyển thư, bưu phẩm trong nước và ngoài nước, và cũng cung cấp dịch vụ tài chính giống như ngân hàng."

Trong bản dịch trên, chúng ta có thể thấy từ "thì" là yếu tố có thể chấp nhận trong giao tiếp bằng lời nói nhưng với văn bản dịch như trường hợp này thì nó đã trở thành yếu tố thừa của câu.

Gợi ý cách dịch (11'): "Chúng ta có thể sử dụng dịch vụ bưu điện khi cần gửi thư hoặc bưu phẩm. Bưu điện thực hiện nhiệm vụ gửi thư, bưu phẩm trong nước và quốc tế, đồng thời đảm nhiệm nghiệp vụ liên quan đến tài chính giống như ngân hàng."

Các minh họa trên cho thấy bản dịch của sinh viên dùng lẫn giữa văn phong nói và viết không chỉ trong bản dịch ngược mà còn tồn tại trong cả bản dịch xuôi. Điều này chứng tỏ ngoài việc trau dồi và rèn luyện ngoại ngữ, sinh viên cũng cần chú ý hơn trong chính ngôn ngữ mẹ đẻ của mình.

\section{* Lối ngũ dụng}

- Văn bản nguồn (12): “한 눈에 보이는 한국 생활"

Bản dịch của sinh viên (12-1): "Nhìn đời sống Hàn Quốc qua một con mắt"

Có thể thấy, bản dịch trên là một bản dịch quá thiên về nghĩa đen, dịch từng từ (word for word) từ tiếng Hàn sang tiếng Việt. Văn bản nguồn ở đây được trích từ một cuốn sách giới thiệu về văn hóa Hàn Quốc, vì vậy, cách diễn đạt mang đặc trưng của ngôn ngữ và văn hóa khiến việc chuyển dịch phong cách ngôn bản khó khăn hơn cho người dịch.

Cách dịch "qua một con mắt" có thể sẽ gây ấn tượng không hay cho người đọc vì người Việt Nam chúng ta thường nói "nhìn đời bằng nửa con mắt" để chỉ sự kênh kiệu, vênh váo hay bất cần. Ngoài ra, văn bản gốc là một cụm danh từ thì người dịch đã chuyển ngữ bằng một cụm động từ cũng làm thay đổi sắc thái của văn bản, tạo cảm giác cứng nhắc hơn.

Gợi ý cách dịch (12'): "Một thoáng Hàn Quốc" / "Khái quát về cuộc sống tại Hàn Quốc"

* Lối dịch thìa/thiếu/sai nội dung

- Văn bản nguồn (13): “만약 지진, 태풍, 홍수, 화재, 전쟁 등 양측에 의해서 불가항력적인 재난이 발생한 경우 영향을 입은 한 측은 하기에 명시한 바, 합작회사의 수행에 관계되는 책임에서 면제된다."

Bản dịch của sinh viên (13-1): "Trong trường hợp phát sinh ra các hiểm họa mà cả hai bên đều bất khả kháng như động đất, bão, lũ, hỏa hoạn, chiến tranh, phía chịu ảnh hưởng được miễn mọi trách nhiệm liên quan đến việc thi hành công ty liên doanh."

Người đọc bản dịch có thể thấy rằng người dịch văn bản trên chưa có sự hiểu biết về điều khoản bất khả kháng thường xuất hiện trong các bản hợp đồng giao dịch nên đã dịch thành "hai bên đều bất khả kháng". Tiếp theo, trong văn bản nguồn có ghi "하기에 명시한 바" nghĩa là "(trách nhiệm) ghi rõ dưới đây" nhưng trong bản dịch, sinh viên đã chuyển thành "mọi trách nhiệm". Người đọc bản dịch có lẽ cũng sẽ cảm thấy khó hiểu trước cụm từ "thi hành công ty liên doanh" của người dịch. Như vậy, bản dịch vừa dịch thiếu cũng vừa dịch sai nội dung cần truyền tải.

Gợi ý cách dịch (13'): “Trong trường hợp xảy ra các sự cố bất khả kháng cho cả 2 phía do động đất, bão, lũ lụt, hỏa hoạn, chiến tranh gây ra thì phía chịu ảnh hưởng sẽ được miễn các trách nhiệm có liên quan đến triển khai công việc của công ty liên doanh trong những điều khoản được liệt kê cụ thể dưới đây."

Trong các bản dịch của sinh viên, chúng tôi còn nhận thấy một số bản dịch chịu ảnh hưởng về cách diễn đạt từ tiếng mẹ đẻ hoặc ngược lại như minh họa dưới đây.

- Văn bản nguồn (14): "국민의 배우자 (F-2-1)의 경우에는 체류기간 안에서 복수 재입국허가서를 발급받을 수 있다. 단, 국민의 배우자 사증을 갖고 있더라도 
이혼소송 중이어서 체류기간이 3 개월씩 연장되는 경우에는 단수 재입국허가서만 발급된다."

Bản dịch của sinh viên (14-1): “Ở trường hợp vợ (chồng) của người trong nước (F-2-1) có thể được cấp giấy cho phép tái nhập cảnh nhiều lần trong thời gian lưu trú. Tuy nhiên ở trường hợp dù mang visa của vợ (chồng) của người trong nước nhưng làm thủ tục li hôn nên cứ mỗi 3 tháng lại gia hạn thời gian lưu trú chỉ được cấp giấy cho phép tái nhập cảnh một lần.” tôi còn phát hiện ra một số lỗi khác xuất hiện trong bài biên dịch của sinh viên như: Lỗi trong cách phiên âm tên của người Hàn Quốc sang chữ Latin hoặc phiên âm tên của người Việt Nam sang chữ Hangeul; chia động từ ở thì chưa phù hợp; sai thông tin về số liệu như tỉ lệ, ngày tháng năm, số lượng; v.v...

Chúng tôi thống kê tỉ lệ sinh viên mắc các lỗi biên dịch về nội dung trong 7 tuần học đầu tiên của học kỳ I như Bảng 2 dưới đây:

Bảng 2. Lỗi biên dịch về nội dung theo các tuần

\begin{tabular}{|c|c|c|c|c|c|c|c|c|c|}
\hline STT & Tên lỗi & Tuần 1 & Tuần 2 & Tuần 3 & Tuần 4 & Tuần 5 & Tuần 6 & Tuần 7 & TB \\
\hline 1 & Lối ngữ pháp & $79,8 \%$ & $73,2 \%$ & $75,5 \%$ & $72,1 \%$ & $69,9 \%$ & $72,7 \%$ & $68,4 \%$ & $73,1 \%$ \\
\hline 2 & Lối chọn lọc từ & $81,8 \%$ & $78,3 \%$ & $69,5 \%$ & $86,1 \%$ & $76,2 \%$ & $75,6 \%$ & $77,2 \%$ & $77,8 \%$ \\
\hline 3 & Lỗi văn phong nói/viết & $60,4 \%$ & $59,6 \%$ & $59,1 \%$ & $60,2 \%$ & $58,7 \%$ & $55,3 \%$ & $50,6 \%$ & $57,7 \%$ \\
\hline 4 & Lối ngữ dụng & $35,9 \%$ & $27,5 \%$ & $30,2 \%$ & $29,8 \%$ & $24,4 \%$ & $16,7 \%$ & $32,8 \%$ & $28,1 \%$ \\
\hline 5 & $\begin{array}{c}\text { Lỗi dịch thừa/thiếu/sai } \\
\text { nội dung }\end{array}$ & $93,7 \%$ & $95,8 \%$ & $84,3 \%$ & $96,7 \%$ & $92,1 \%$ & $89,6 \%$ & $90,8 \%$ & $91,9 \%$ \\
\hline
\end{tabular}

Ở bản dịch trên, người dịch đã dịch từ "국민" (người dân / nhân dân) trong cụm "국민의 배우자" thành "người trong nước". Đây là cách nói chỉ sử dụng trong tình huống tất cả chủ thể giao tiếp đều là người Hàn Quốc. Cách dịch này sẽ làm cho người đọc bản dịch cảm thấy mơ hồ, khó hiểu vì không biết "người trong nước" là ai và có ai là "người ngoài nước" hay không. Ngoài ra, bản dịch này còn thiếu sự xuất hiện của chủ ngữ cũng khiến nội dung bản dịch bị tối nghĩa.

Gợi ý cách dịch (14'): "Đối với trường hợp vợ (chồng) của công dân Hàn Quốc (visa F-2-1) thì có thể nhận giấy phép tái nhập cảnh nhiều lần trong thời hạn cư trú. Riêng trường hợp đang sử dụng visa tư cách vợ (chồng) của người Hàn Quốc nhưng đang trong quá trình tố tụng li hôn thì chỉ được phép gia hạn thời hạn cư trú mỗi lần là 3 tháng và chỉ được cấp phép tái nhập cảnh một lần.”

Ngoài các minh họa điển hình trên, chúng

\subsection{Lỗi biên dịch về hình thức}

Trong thực tế công tác biên dịch hiện nay, hầu hết các biên dịch viên đều thực hiện nghiệp vụ của mình trên máy tính. Vì vậy, khả năng sử dụng thành thạo các công cụ xử lý văn bản được chúng tôi coi trọng trong quá trình dạy - học học phần "Biên dịch" cho sinh viên.

Qua khảo sát, có 96,6\% sinh viên đã tham gia học phần Tin học cơ sở. Tuy nhiên, có $68,9 \%$ sinh viên chưa thành thạo các thao tác trên máy tính và các kỹ năng xử lý văn bản như: không có khả năng gõ 10 ngón với cả tiếng Việt và tiếng Hàn; chưa nhận biết chính xác vị trí phím chữ Hangeul; không căn chỉnh lề, căn chỉnh giãn dòng; không căn chỉnh phông chữ / cỡ chữ; ngắt dòng ở vị trí chưa phù hợp dẫn đến người đọc có thể hiểu sai thông tin định truyền tải hoặc trình bày hình thức văn bản chưa đẹp; không lưu file trong quá trình dịch... Thậm chí vẫn có trường hợp 
sinh viên không biết tìm được phông chữ ở đâu trên thanh công cụ xử lý văn bản.

Các lỗi về thao tác và xử lý văn bản trên gây ra những bất tiện trong quá trình sinh viên thực hiện công việc biên dịch của mình: thời gian biên dịch của họ thường kéo dài hơn so với các sinh viên thành thạo các thao tác xử lý văn bản. Do đó trong quá trình giảng dạy, ngoài việc hướng dẫn liên quan trực tiếp đến nội dung của học phần, giáo viên còn phải dành thời gian để hướng dẫn sinh viên các kỹ năng xử lý văn bản, cụ thể các lỗi biên dịch của sinh viên về mặt hình thức từ tuần 1 đến tuần 7 được chúng tôi tổng hợp như Bảng 3 dưới đây:

\subsection{Kết quả đánh giá giũa học kỳ}

Trong quá trình dạy học học phần biên dịch theo từng tuần, sinh viên được các bạn học cùng lớp cùng tham gia góp ý về bài dịch của họ về cả nội dung và hình thức. Sinh viên cũng được giáo viên chỉ ra các lỗi biên dịch cùng các gợi ý sửa lỗi, sau đó sinh viên được yêu cầu rèn luyện các kỹ năng biên dịch từ tuần 1 đến tuần 7, chúng tôi đã tổ chức bài thi kiểm tra đánh giá giữa học kỳ ở tuần thứ 8 nhằm kiểm tra sự tiến bộ của sinh viên. Kết quả tổng hợp phân tích lỗi biên dịch của sinh viên trong bài thi giữa học kỳ về nội dung như ở Bảng 4 và về hình thức như ở Bảng 5 dưới đây:

Bảng 3. Lỗi biên dịch về hình thức

\begin{tabular}{|c|c|c|c|c|c|c|c|c|c|}
\hline STT & Tên lỗi & Tuần 1 & Tuần 2 & Tuần 3 & Tuần 4 & Tuần 5 & Tuần 6 & Tuần 7 & TB \\
\hline 1 & Không căn chỉnh lề & $65,4 \%$ & $51,7 \%$ & $48,5 \%$ & $42,8 \%$ & $32,6 \%$ & $21,3 \%$ & $9,8 \%$ & $38,9 \%$ \\
\hline 2 & Không căn chỉnh giãn dòng & $67,9 \%$ & $60,2 \%$ & $58,1 \%$ & $53,4 \%$ & $45,6 \%$ & $40,3 \%$ & $37,7 \%$ & $51,9 \%$ \\
\hline 3 & Không căn chỉnh phông chữ & $53,5 \%$ & $50,8 \%$ & $51,7 \%$ & $48,6 \%$ & $45,2 \%$ & $42,9 \%$ & $40,1 \%$ & $47,5 \%$ \\
\hline 4 & $\begin{array}{c}\text { Không sử dụng đúng định } \\
\text { dạng của văn bản gốc (in đậm, } \\
\text { in nghiêng, logo, ký hiệu...) }\end{array}$ & $91,9 \%$ & $87,4 \%$ & $79,7 \%$ & $78,1 \%$ & $70,5 \%$ & $63,2 \%$ & $55,6 \%$ & $75,2 \%$ \\
\hline 5 & $\begin{array}{c}\text { Sai chính tả (sai dấu, sai ký } \\
\text { tự, viết tên riêng không in } \\
\text { hoa,...) }\end{array}$ & $92,1 \%$ & $90,3 \%$ & $91,2 \%$ & $89,6 \%$ & $93,4 \%$ & $87,5 \%$ & $86,9 \%$ & $90,1 \%$ \\
\hline
\end{tabular}

Bảng 4. Lỗi biên dịch về nội dung trong bài thi giữa học kỳ

\begin{tabular}{|c|c|c|}
\hline STT & Tên lỗi & Tỉ lệ sinh viên mắc lỗi \\
\hline 1 & Lỗi ngữ pháp & $71,4 \%$ \\
\hline 2 & Lỗi chọn lọc từ & $89,3 \%$ \\
\hline 3 & Lỗi văn phong nói / viết & $57,1 \%$ \\
\hline 4 & Lỗi ngữ dụng & $10,1 \%$ \\
\hline 5 & Lỗi dịch thừa / thiếu / sai nội dung & $100 \%$ \\
\hline
\end{tabular}

Bảng 5. Lỗi biên dịch về hình thức trong bài thi giữa học kỳ

\begin{tabular}{|c|c|c|}
\hline STT & Tên lỗi & Tỉ lệ sinh viên mắc lỗi \\
\hline 1 & Không căn chỉnh lề & $7,1 \%$ \\
\hline 2 & Không căn chỉnh giãn dòng & $35,7 \%$ \\
\hline 3 & Không căn chỉnh phông chữ & $42,9 \%$ \\
\hline 4 & $\begin{array}{c}\text { Không sử dụng đúng định dạng của văn bản gốc (in đậm, in } \\
\text { nghiêng, logo, ký hiệu...) }\end{array}$ & $50,0 \%$ \\
\hline 5 & Sai chính tả (sai dấu, sai ký tự, viết tên riêng không in hoa,...) & $85,7 \%$ \\
\hline
\end{tabular}


Qua hai bảng tổng hợp phân tích lỗi biên dịch của sinh viên ở trên, chúng ta có thể thấy sau 7 tuần được giáo viên cũng như các bạn học cùng tham gia góp ý, hướng dẫn, chỉnh sửa bài biên dịch thì sinh viên đã dần nhận thức và có sự lưu ý hơn trong các bản dịch tiếp theo của mình.

Về mặt nội dung, có thể nhận thấy sự chuyển biến chưa lớn, thể hiện qua tỉ lệ sinh viên mắc các lỗi vẫn chiếm đại đa số. Nguyên nhân của hiện tượng này là do các lỗi biên dịch về nội dung có liên quan chặt chẽ với kiến thức về từ vựng, ngữ pháp, kiến thức nền về lĩnh vực biên dịch,... của sinh viên. Để khắc phục các lỗi này đòi hỏi phải có thời gian để họ ôn luyện lại các kiến thức thực hành tiếng đã được học trong 4 học kỳ trước đó cũng như tiếp tục củng cố, bổ sung vốn từ vựng, dành thêm nhiều thời gian nghiên cứu và tìm hiểu các văn bản trong đời sống.

Về mặt hình thức, chúng tôi cho rằng phần lớn đều là các lỗi xuất phát từ yếu tố kỹ thuật. Vì vậy, chỉ cần người học nhận thức và lưu tâm trong quá trình biên dịch thì các lỗi này có thể được hạn chế ở mức tối đa. Riêng về vấn đề sai chính tả, ngoài yếu tố kỹ thuật, chúng tôi còn phán đoán lỗi này liên quan đến kiến thức từ vựng, phát âm của sinh viên do có nhiều trường hợp, trong các bản dịch, người học dùng các từ có cách viết tương tự với từ phù hợp hoặc chuyển phụ âm căng thành phụ âm bật hơi và ngược lại.

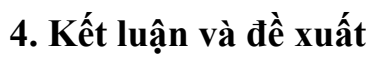

Từ việc nghiên cứu phân tích bài biên dịch của sinh viên năm thứ ba Khoa Ngôn ngữ và Văn hóa Hàn Quốc, học kỳ I năm học 20172018, chúng tôi đã nhận diện một số dạng lỗi cơ bản thường xuyên lặp lại trong phần biên dịch của người học. Các lỗi về nội dung được minh họa và phân tích cụ thể như lỗi ngữ pháp, lỗi chọn lọc từ, lỗi văn phong nói/viết, lỗi ngữ dụng, lỗi dịch thừa/thiếu/sai nội dung chủ yếu xuất phát từ nguyên nhân kiến thức từ vựng, kiến thức ngữ pháp, sự ảnh hưởng trong tư duy ngôn ngữ giữa tiếng Việt và tiếng Hàn của người học, do người học chưa có cơ hội tiếp xúc với hình thức văn bản cần dịch, v.v...

Theo Lâm Quang Đông (2007: 26-27), "Người làm công tác dịch thuật cần nhiều loại kiến thức: ngôn ngữ, văn hoá, kiến thức phổ thông hay kiến thức nền (general or background knowledge) và kiến thức chuyên môn. Họ cần phải thông thạo, có vốn từ vựng phong phú, hiểu biết thấu đáo những vấn đề ngôn ngữ học của cả hai ngôn ngữ, hiểu biết những tương đồng và khác biệt giữa hai ngôn ngữ không những chỉ về ngữ pháp mà còn về ngữ nghĩa và ngữ dụng. Những hiểu biết đó gắn chặt với tri thức văn hoá về đất nước, con người, lối sống, thói quen, phong tục tập quán của hai cộng đồng ngôn ngữ. Đến lượt chúng, tri thức văn hoá lại phải dựa trên một nền tảng tri thức bách khoa vững chắc và liên tục được cập nhật. Cuối cùng, mỗi một chuyên ngành có những thuật ngữ, cách diễn đạt riêng, phong cách riêng, đòi hỏi người làm công tác dịch thuật phải hiểu được chí ít là ý nghĩa, nội hàm của chúng, dẫu rằng không thể sâu như một nhà chuyên môn."

Những yêu cầu đối với một biên phiên dịch viên về các kiến thức như trên không phải là điều dễ dàng đối với những người mới bắt đầu tham gia các học phần về biên - phiên dịch như đối tượng của bài nghiên cứu này là các sinh viên năm thứ ba. Vì vậy, để khắc phục các lỗi về nội dung trong các bản dịch của sinh viên, chúng tôi xin đưa ra một số đề xuất như sau:

+ Củng cố kiến thức ngữ pháp cho sinh viên, trong đó lưu ý đến các tiểu từ, phân biệt các động từ thuần Hàn, các động từ có âm Hán kết thúc bằng 하다, đặc biệt lưu ý đến trật tự câu, trật tự từ trong các cụm từ v.v...

+ Củng cố kiến thức từ vựng cho sinh viên; giải thích kèm theo ngữ cảnh sử dụng của từ vựng; lưu ý sự đa nghĩa của từ vựng V.V...

+ Khuyến khích sinh viên phát triển các kỹ năng liên quan đến biên dịch như: kỹ năng đọc, kỹ năng nghiên cứu, kỹ năng phân tích 
văn bản. Khuyến khích họ đọc nhiều các tài liệu trong thực tế để nâng cao kiến thức nền, sự hiểu biết về văn phong, hình thức trình bày cũng như sự hiểu biết về các từ vựng thường xuyên được sử dụng trong các lĩnh vực cụ thể.

+ Giáo viên hướng dẫn và cùng sinh viên dành thời gian để tìm hiểu, phân tích văn bản nguồn, cùng xác định loại hình văn bản, hướng dẫn tra cứu vì "việc phân tích văn bản nguồn thuộc giai đoạn tiếp nhận là giai đoạn để nguời dịch tìm hiểu văn bản nguồn và thực hiện tất cả nhũ̃ng bước chuẩn bị quan trọng nhất cho giai đoạn tái tạo văn bản" (Lê Hoài Ân, 2011: 250).

+ Tạo cơ hội cho người học tích cực, chủ động cùng thảo luận về bản dịch của nhau và cùng góp ý để học hỏi các cách dịch khác nhau và cùng nhau đưa ra phương án dịch tốt nhất.

Các lỗi về hình thức được phát hiện và nêu ra trong bài nghiên cứu này sau quá trình người học được yêu cầu triển khai bài biên dịch trên máy tính chủ yếu liên quan đến yếu tố kỹ thuật được liệt kê ra gồm: căn chỉnh lề, căn chỉnh giãn dòng, căn chỉnh phông chữ, sai định dạng của văn bản nguồn, các lỗi chính tả,... có thể trước đây chưa được giáo viên và sinh viên quan tâm do bản dịch của sinh viên là các bản viết tay.

Ưu điểm của việc thao tác trên máy tính là sinh viên được trải nghiệm cảm giác làm việc thật sự trong thực tế của các biên dịch viên, biết được thời gian cần thiết để hoàn thành một bản dịch cụ thể, vai trò quan trọng của hình thức trong trình bày bản dịch đồng thời cũng là cơ hội để họ rèn luyện các kỹ năng thao tác máy tính thành thạo hơn. Ngoài ra, thay vì giáo viên và sinh viên chỉ có cơ hội trao đổi, thảo luận, hướng dẫn về một số lượng hạn chế các bản dịch được trình bày trên bảng thì khi kết hợp sử dụng máy tính với thiết bị máy chiếu có sã̃n trên lớp học, họ sẽ có thêm nhiều cơ hội để xem các bản dịch khác nhau trong một khoảng thời gian ngắn.
Để khắc phục các lỗi về hình thức, chúng tôi xin đưa ra các đề xuất như sau:

+ Khuyến khích các giờ học biên dịch trong thời gian sắp tới sẽ tiếp tục triển khai thao tác dịch thuật trên máy tính. Mặc dù điều kiện về cơ sở vật chất trong thời điểm hiện tại của Nhà trường chưa có đủ các phòng máy phục vụ cho các lớp học biên - phiên dịch nhưng hầu hết các sinh viên đã có thể tự trang bị máy tính xách tay cho mình nên chúng tôi cho rằng việc triển khai giờ học như vậy không phải là việc khó khăn.

+ Các học phần Tin học cơ sở có thể cần bổ sung thời lượng thực hành cho sinh viên hoặc có các phương án để người học tự rèn luyện, sau đó kiểm tra kết quả của họ để giảm thiểu các lỗi sai về hình thức do yếu tố kỹ thuật như trên.

+ Mở câu lạc bộ Tin học tại Khoa, trong đó có nội dung tập gõ bàn phím chữ Hangeul và làm quen với cách trình bày văn bản của Hàn Quốc.

\section{Tài liệu tham khảo}

\section{Tiếng Việt}

Lê Hoài Ân (2011). Một số kiến nghị nhằm nâng cao chất lượng giảng dạy biên dịch. Tạp chí Khoa hoc ĐHQGHN - Ngoại ngũ, 27, tr. 246-255.

Lâm Quang Đông (2007). Về tính chuyên nghiệp của nghề dịch thuật. Ngôn ngũ và Đời sống, 10(144), tr. 25-28.

Nguyễn Thị Minh Tâm, Nguyễn Diệu Hồng, Trần Thị Long (2017). Khảo sát thực trạng sử dụng tiếng Anh trong các biển hướng dẫn du lịch tại một số điểm du lịch ở Miền Bắc Việt Nam. Nghiên cúu Nước ngoài, 33(2), tr. 90-104.

\section{Tiếng Anh}

El Shafey, F. A. (1985). Compounding in English and Arabic, Implications for Translation Methodology (Unpublished master's thesis). Faculty of Arts, Cairo University.

El Zeini, N. T. (1994). Criteria for the Evaluation of Translation: A Pragma-stylistic approach (Unpublished doctoral dissertation). Faculty of Arts, Cairo University.

Massoud, M. F. (1988). Translate to Communicate, A Guide for Translators. New York: David C. Cook Foundation. 


\title{
A SURVEY ON THE THIRD YEAR STUDENTS' TRANSLATION MISTAKES AT THE UNIVERSITY OF LANGUAGES AND INTERNATIONAL STUDIES - VNU
}

\author{
Do Thuy Hang \\ Faculty of Korean Language and Culture, VNU University of Languages and International Studies, \\ Pham Van Dong, Cau Giay, Hanoi, Vietnam
}

\begin{abstract}
This paper presents the study of translation mistakes by the third year students of the University of Languages and International Studies (ULIS) - VNU. Based on an analytical framework of translation mistakes in terms of content and form mistakes, the authors carried out a survey of 406 translation assignments from week 1 to week 7 and the mid-term tests by 58 students in the first semester of the academic year of 2017-2018. The survey result shows a variety of translation mistakes related to grammar, word choice, stylistics, pragmatics, and even typing. Finally, the authors propose some solutions to improve students' translation quality in the next classes of translation.

Keywords: mistakes, translation, Korean
\end{abstract}

